\title{
Editorial
}

\section{Economía circular un paso hacia un planeta más verde}

A nivel mundial existen múltiples procesos de fabricación que llevan asociados un coste ambiental, desde el punto de vista de producir hasta que acaba el ciclo de vida útil del producto o servicio. El sistema de producción actual está basado en un concepto lineal, que engloba 3 aspectos principales producir, usar y tirar. El modelo lineal caracteriza porque en él, las empresas producen bienes y servicios, los consumidores los utilizan y consumen, las empresas sacan nuevos productos y servicios, los consumidores dejan de utilizar los que se han quedado viejos o se estropean y compran los nuevos. Con la entrada cada vez mayor de nueva tecnología y el aumento del poder adquisitivo y facilidades de inversión estos ciclos y/o líneas son más cortos y producen una gran huella ambiental.

Para contrarrestar esta problemática, nace o surge un nuevo modelo más amigable con el medio ambiente conocido como Economía Circular, siendo un modelo en donde se favorece el aprovechamiento de recursos y la reducción de las materias primas. De esta forma se convierte en una alternativa al actual modelo lineal. la economía circular aboga por la optimización de los materiales y residuos, alargando su vida útil. De este modo se huye del actual sistema lineal de 'usar y tirar' y se apuesta por otro respetuoso con el medio ambiente y basado en la prevención, la reutilización, reparación y reciclaje (Figura 1).

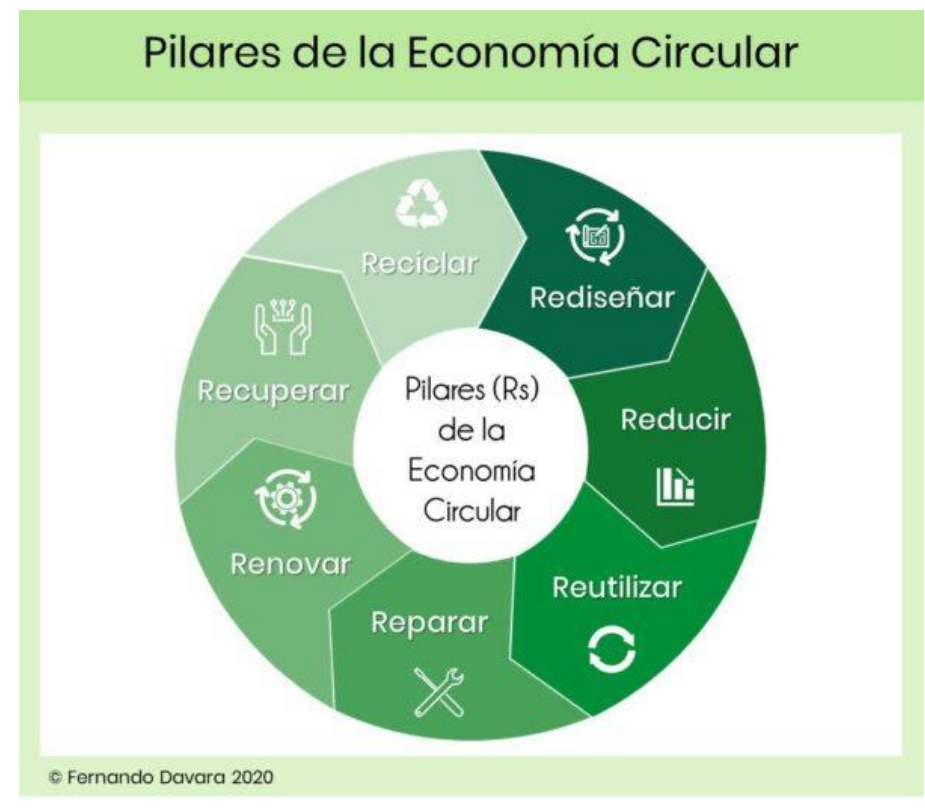

Figura 1. Pilares de la economía Circular

Pero, ¿qué aspectos se tienen en cuenta a la hora de aplicar el modelo de economía circular?:

Este modelo está basado en siete aspectos principales conocidos como las 7R que se describen como reflexionar, rechazar, reducir, reutilizar, reparar, reciclar y recuperar. Existen diferentes rasgos que definen cómo debe funcionar la economía circular: 
El residuo se convierte en recurso: Todo el material biodegradable vuelve a la naturaleza y el que no es biodegradable se reutiliza. Además, mediante un segundo uso se reintroduce en el circuito económico aquellos productos que ya no corresponden a las necesidades iniciales de los consumidores.

La reutilización: reusar ciertos residuos o ciertas partes de los mismos, que todavía pueden funcionar para la elaboración de nuevos productos.

La reparación: encontrar una segunda vida a los productos estropeados.

El reciclaje: utilizar los materiales que se encuentran en los residuos.

La valorización: aprovechar energéticamente los residuos que no se pueden reciclar.

Energía de fuentes renovables: eliminación de los combustibles fósiles para producir el producto, reutilizar y reciclar.

En resumen, la economía circular trata de convertir los residuos en nuevas materias primas. Y además, generar empleo en el contexto de la llamada economía verde. La impulsora de este modelo fue Ellen MacArthur y así explica cómo funciona este modelo en el siguiente vídeo de su fundación por la economía circular: https://youtu.be/RstFV_n6wRg

"Si la civilización quiere sobrevivir, debe vivir del interés de la naturaleza, no del capital”. Ronald Wright. Escritor.

\section{Javier Eduardo Sánchez Ramírez}

PhD. Investigador

Depuración de Aguas del Mediterráneo

La Revista Ingeniería y Región cuenta con la Licencia

Creative Commons Atribución (BY), No Comercial (NC) y Compartir Igual (SA)

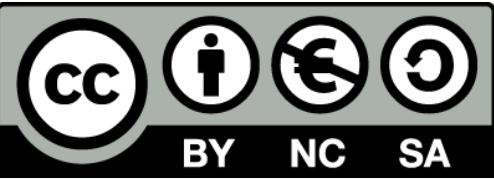

